\section{Aflatoxin B1 risk management in Parmigiano Reggiano dairy cow feed}

\author{
Giorgia Canestrari, ${ }^{1}$ Barbara Ricci, ${ }^{1}$ \\ Valentina Pizzamiglio, ${ }^{2}$ \\ Alberto Biancardi, ${ }^{3}$ Pierluigi Piazza, ${ }^{3}$ \\ Giuseppe Merialdi, ${ }^{4}$ Giovanni Tosi, ${ }^{5}$ \\ Federica Giacometti, ${ }^{1}$ Marco Nocetti, \\ Mattia Fustini, ${ }^{1}$ Andrea Serraino, \\ Andrea Formigoni ${ }^{1}$ \\ 'Department of Veterinary Sciences, \\ Alma Mater Studiorum-University of \\ Bologna, Ozzano Emilia (BO); \\ 2 Parmigiano Reggiano Cheese \\ Consortium, Reggio Emilia (RE); \\ ${ }^{3}$ Institute for Experimental Veterinary \\ Medicine of Lombardy and Emilia \\ Romagna, Brescia; ${ }^{4}$ Institute for \\ Experimental Veterinary Medicine of \\ Lombardy and Emilia Romagna, Bologna; \\ 5 Institute for Experimental Veterinary \\ Medicine of Lombardy and Emilia \\ Romagna, Forlì, Italy
}

\begin{abstract}
This study investigated aflatoxin B1 (AFB1) contamination in dairy cow feed and the risk management of AFB1 content in concentrates undertaken by feed industries in the Parmigiano Reggiano area. Data on aflatoxin contamination risk management applied in 29 feed industries were collected and the AFB1 content of 70 feed samples was analysed. Data were collected within the framework of a quality control programme promoted by the Parmigiano Reggiano Consortium in 2013 and 2014. Audit results showed that the control procedures to prevent AFB1 contamination mainly focused on maize and its by-products. AFB1 concentration resulted lower than $5 \mathrm{ppb}$ [legal European Union (EU) limit] in all samples; in one out of 70 samples, AFB1 content was $3.8 \mathrm{ppb}$ and in all the other samples it was lower than 3 ppb. Results showed that AFB1 risk management applied by Italian feed industries effectively monitors AFB1 levels in feed below the EU legal limit.
\end{abstract}

\section{Introduction}

Aflatoxins are secondary metabolites produced by different fungi of the species Aspergillus, mainly A. flavus and A. parasiticus, but also A. nominus and A. tamarii (Kurtzman et al., 1987; Goto et al., 1997), the strain A. pseudotamarii isolated by Ito et al. (2001), and also A. niger, A. wentii, Penicillum citrinum and $P$. frequentans (Caloni and Nebbia, 2009). These organisms may contaminate agriculture products, feedstuff and food. The aflatoxin group includes aflatoxin B1 (AFB1), B2, G1 and G2, and their hydroxylated metabolites can be found in milk. Aflatoxins M1 (AFM1) and M2 are the metabolites of AFB1 and B2 respectively. AFM1 is the most commonly occurring aflatoxin detected in milk of mammals exposed to AFB1 ingestion. AFB1 is classified as Group 1 (carcinogenic to humans) while AFM1 is classified as Group 2B (possibly carcinogenic to humans) by the International Agency for Research on Cancer (IARC) (Caloni and Nebbia, 2009).

Aflatoxin contamination risk is generally higher in geographical regions with a tropical or subtropical climate, but the abnormal hot and drought-growing seasons of maize have raised problems in crop management especially in Southeast Europe (Serraino et al., 2003; Trevisani et al., 2014). Maize grain, which is normally used to feed dairy cattle, is produced with the use of irrigation systems in this region. Maize can be infected by moulds when hot and dry environmental conditions occur during the pre-harvest phase, and weeds and crop disease contribute to grain contamination by aflatoxin (Giorni et al., 2007; Prandini et al., 2009; Kebede et al., 2012). In 2003 and 2012, unfavourable weather conditions, such as temperatures above $30^{\circ} \mathrm{C}$ and the lack of precipitation over an extended period, caused a massive contamination of maize in Northern Italy resulting in an increase in AFM1 in cow's milk (Canever et al., 2004; Marchetti et al., 2013).

The carryover of aflatoxin from cattle feed to milk depends on the animal breed, the lactation period and udder infections (Masoero et al., 2007). The average value is approximately $2.5 \%$, but a direct relation between carryover rate and milk yield was found with carryover percentages as high as $6.2 \%$ in high-yielding dairy cows with a production of up to $40 \mathrm{~L}$ of milk per day (Veldman et al., 1992). Despite the high individual variability, the equation proposed by Veldman et al. (1992) is used to estimate the carryover of AFM1 in a whole dairy herd:

$$
\begin{gathered}
\text { AFM1 }(\mathrm{ng} / \mathrm{kg} \text { milk })=1.19 \times \mathrm{AFB} 1 \\
(\mu \mathrm{g} / \mathrm{cow} / \text { day })+1.19
\end{gathered}
$$

Using this equation is it possible to assume that, in order to obtain a concentration of AFM1 below the maximum limit allowed by EU Regulation 1881/2006 (European Commission, 2006), the average intake of AFB1 must be less than $40 \mu \mathrm{g} /$ day. Considering that a complementary feed can be given to a dairy cow at levels of $>10 \mathrm{~kg} /$ day and that its aflatoxin contamination limit is 5 ppb (EC Regulation 574/2011; European Commission, 2011), it is easy to
Correspondence: Giorgia Canestrari, Department of Veterinary Sciences, Alma Mater StudiorumUniversity of Bologna, via Tolara di Sopra 50, 40064 Ozzano Emilia (B0), Italy.

Tel: +39.051.2097371 - Fax: +39.051.2097346.

E-mail: giorgia.canestrari@unibo.it

Key words: Aflatoxins; Feed; Dairy cows Parmigiano Reggiano.

Conflict of interest: the authors declare no potential conflict of interest.

Received for publication: 26 May 2015.

Revision received: 24 June 2015.

Accepted for publication: 24 June 2015.

This work is licensed under a Creative Commons Attribution-NonCommercial 4.0 International License (CC BY-NC 4.0).

(C) Copyright G. Canestrari et al., 2016 Licensee PAGEPress, Italy

Italian Journal of Food Safety 2016; 5:5291 doi:10.4081/ijfs.2016.5291

deduce that it is possible produce non compliant milk even feeding cows with compliant (5 ppb) complementary feed. For this reason several integrated dairy chains require to the feed industry a lower AFB1 content in their products and they provide a better information for dairy farmers. In 1993 the Parmigiano Reggiano (PR) Consortium signed a protocol with feed industries to reduce the AFB1 content in concentrates for dairy cow feed to a level below 3 ppb instead of the 5 ppb EU limit.

This work reports the results of an investigation, performed in the Parmigiano Reggiano area, on AFB1 contamination in dairy cows complementary feed and on the related risk management implemented by feed industries.

\section{Materials and Methods}

During 2013 and 2014, in the framework of a quality control program performed by the PR Consortium (Ricci et al., 2015), data on AFB1 risk management were collected in 29 feed industries. The quality control program was based on a voluntary agreement between the feed industries and the PR Consortium. The agreement considered the application of requirements defined by the specification of Parmigiano Reggiano cheese (for example a ban on the use of cotton seed, canola and others feedstuffs) and additional requirements defining higher processing and composition standards compared to EU Regulation $\mathrm{n}^{\circ}$ 574/2011 (European Commission, 2011). The additional requirements regard the aflatoxin content (fixed at $3 \mathrm{ppb}$ instead of $5 \mathrm{ppb}$ ), 
absence of gossypol, absence of volatile mustard oil, the implementation of procedures to avoid cross-contamination with prohibited raw materials like rice, rapeseed and cotton in dairy cow feed.

Audits were performed twice in each of the 29 feed industries, once in 2013, collecting one feed sample in each plant (totally 29 samples) and the second in 2014 collecting 41 feed samples, more than one in each plant.

Samples collected in 2013 were analysed for the quantitative detection of AFB1 by Ridascreeen ${ }^{\circledR}$ Aflatoxin B1 30/15 Biopharm kit (Darmstadt, Germany) whereas the samples collected in 2014 were first screened for total Aflatoxin content by I'Screen Afla (Tecna, Trieste, Italy) and AFB1 was quantified only in samples with an Aflatoxin B total content higher than $3 \mathrm{ppb}$ by a LC-MS/MS method (Biancardi and Dall'Asta, 2014).

\section{Results}

Audit results showed that the AFB1 contamination risk management applied by feed industries mainly focused, as expected, on maize and its by-products. Procedures performed by feed industries to reduce AFB1 contamination of maize included: i) purchase of maize in geographic areas with a low AFB1 contamination risk due to favourable environmental conditions or to a particular organisation of the maize supply chain; ii) specific commercial agreements with suppliers that included a maximum limit of AFB1 concentration; iii) a high frequency (up to 100\%) of delivered maize analysis; iv) the selection of maize on the basis of AFB1 content and differentiated use of AFB1 in feed for different species (for example low AFB1 contaminated maize for dairy cow feed and high AFB1 contaminated maize for swine feed); v) high frequency of maize purchasing reducing storage time in the feed mill. More details on AFB1 risk management are reported in Table 1. The AFB1 content was $<2$ ppb in 28 out of 29 samples
(96.6\%) collected during 2013 and $3.8 \mathrm{ppb}$ in the last sample. In 41 samples collected during 2014 , the AF total content was below the limit of detection (2 ppb), in the range $2-3 \mathrm{ppb}$, and $>3$ ppb (up to $4 \mathrm{ppb}$ ) in 14 (34.1\%), 24 (58.5\%) and $3(7.3 \%)$ samples, respectively. The 3 samples showing aflatoxin contamination $>3 \mathrm{ppb}$ were subsequently analysed by LC-MS/MS and AFB1 concentration was $<1 \mathrm{ppb}$ in all these samples.

\section{Discussion}

Few data are available on feed materials originating from Europe (European Food Safety Authority, 2004) as aflatoxin formation was previously considered to occur mainly in geographic regions with a tropical or subtropical climate. On the other hand, AFB1 contamination of feed and feed ingredients, mainly maize, appears to be a problem in southern Europe, and the contamination level is strongly influenced by climate conditions. Out of 533 maize samples for animal feed collected in Northern Italy during the period 1995-1999, Pietri et al. (2004) reported high positive rates (42.9\%), although levels were generally very low (mean concentration between 1.3 and 5.1 ppb during years) with the exception of 2 samples contaminated with AFB1 $>100 \mathrm{ppb}$ and 5 samples >20 ppb. Minervini et al. (1998) analysed 197 dairy cow feed samples and found all of them $<5 \mathrm{ppb}$ and another 124 maize samples where only 9 showed values between 5 and $20 \mathrm{ppb}$, with no samples $>20 \mathrm{ppb}$. In the Lombardy region (1999-2000) 830 dairy cows feed samples were analysed and all feedstuffs showed AFB1 levels $<5$ ppb (Amodeo, 2001).

On the contrary, during the 2003 crisis, several feed samples were analysed in dairy farms where AFM1 milk contamination was above the legal limit of $50 \mathrm{ppt}$. The results showed that $58.9 \%$ of complementary feeds and from 14.48 to $66.66 \%$ of maize and maize products exceeded the EU legal limit (Canever et al., 2004). A study performed from the beginning of 2004 to the end of 2005 reported that AFB1 in cattle feed was higher than the maximum limit in $8.1 \%$ of feed samples, whereas during 2005 found aflatoxin levels constantly below the limits of EU regulations (Decastelli et al., 2007). More recently, a large 2012 survey conducted on corn produced in Northern Italy analysed 31,326 samples collected at storage plants. The results showed that AFB1 contamination above the EU limit of 20 ppb was detected in samples representative of about 784,000 tons of corn, corresponding to $45.2 \%$ of the total production (Causin, 2013).

The results of the present study showed that no sample had AFB1 levels above the EU legal limit of $5 \mathrm{ppb}$ in the investigated feed mills. Moreover, auditing showed that a good level of AFB1 risk management has been achieved by Italian feed industries to counteract the unfavorable climatic conditions arising in some years. The special attention paid by the feed industry to maize AF contamination is probably the result of the two seasonal crises in 2003 and 2012 when unfavorable climatic conditions led to a massive AFB1 contamination of maize with up to $50 \%$ of national maize production non-compliant with EU Regulations and unsuitable for feeding milking cows (Marchetti et al., 2013). As a consequence, monitoring was stepped up by all the dairy production chains, including feed manufacturers and health authorities, also thanks to the availability of rapid and less expensive detection kits to test aflatoxin contamination in raw materials. No limit is reported for AFM1 in cheeses in the European Community legislation, but the provisional limit of 450 ppt was fixed for hard and long maturing cheeses by the Italian Ministry (Italian Ministry of Health, 2004). An investigation performed on Grana Padano cheese produced with naturally contaminated milk showed that AFM1 concentration levels increase 4.5-fold in cheeses (Manetta et al., 2009). This guarantees that the level of AFM1 contamination of cheese will be lower than the $450 \mathrm{ppt}$ limit even when milk with an AFM1 contamination above the legal limit (50 ppt) is used.

Table 1. Actions taken by twenty-nine feed industries to reduce maize aflatoxin B1 contamination in 2013 and 2014.

\begin{tabular}{lcc} 
Type of action & $\begin{array}{c}\text { Feed industries implementing the action (n) } \\
\text { Year 2013 }\end{array}$ \\
$\begin{array}{l}\text { Year } 2014 \\
\text { Testing 100\% of maize consignments }\end{array}$ & 22 \\
High frequency (below 100\%) of delivered maize analysis & 21 & 4 \\
\hline Definition of specific commercial agreements with suppliers & 7 & 6 \\
Maize purchase in geographic areas with low risk of AFBl contamination & 1 & 0 \\
\hline Selection of maize on the basis of AFB1 content and its differentiated use in feed for different species & 1 & 7 \\
\hline High frequency of maize purchasing and reduction of storage time in the feed mill & 7 \\
\hline
\end{tabular}

AFB1, aflatoxin B1. 


\section{Conclusions}

The application of a voluntary agreement to reduce the AFB1 contamination of feedstuffs further reduces the health risk for consumers.

\section{References}

Amodeo P, 2001. Aflatossine nel latte e negli alimenti zootecnici. In: Regione Lombardia, ed. Rischio di aflatossine nel latte: linee guida per la produzione e l'acquisto di alimenti zootecnici. Regione Lombardia, Milan, Italy, pp 7-28.

Biancardi A, Dall'Asta C, 2014. A simple and reliable liquid chromatography-tandem mass spectrometry method for the determination of aflatoxin B1 in feed. Food Addit Contam A 31:1736-43.

Caloni F, Nebbia C, 2009. Micotossine. In: Nebbia C, ed. Residui di farmaci e contaminanti ambientali nelle produzioni animali. EdiSES, Naples, Italy, pp 453-80.

Canever A, Serraino A, Rosmini R, 2004. Presenza di aflatossine nei mangimi destinati all'alimentazione animale. In: Proceedings of the 14th National Congress of AIVI, Santuario di Vicoforte (CN), Italy. AIVI, Ozzano dell'Emilia (BO), Italy, pp 451-5.

Causin R, 2013. Mycotoxins contamination in Italy and management experiences. Available from: www.micotossine.it/public/ pag_2029.pdf

Decastelli L, Laia J, Gramaglia M, Monaco A, Nachtmann C, Oldano F, Ruffier M, Sezian A, Bandirola C, 2007. Aflatoxins occurrence in milk and feed in Northern Italy during 2004-2005. Food Control 18:1263-6.

European Commission, 2006. Regulation of the European Parliament and of the Council of 19 December 2006 setting maximum levels for certain contaminants in foodstuffs, 1881/2006/EC. In: Official Journal, L 364/5, 20/12/2006.
European Commission, 2011. Regulation of the European Parliament and of the Council of 16 June 2011 amending Annex I to Directive 2002/32/EC of the European Parliament and of the Council as regards maximum levels for nitrite, melamine, Ambrosia spp. and carry-over of certain coccidiostats and histomonostats and consolidating Annexes I and II thereto, 574/2011/EC. In: Official Journal, L 159/7, 17/06/2011.

European Food Safety Authority, 2004. Opinion of the Scientific Panel on Contaminants in the Food Chain on a request from the Commission related to Aflatoxin B1 as undesirable substance in animal feed. EFSA J 39:1-27.

Giorni P, Magan N, Pietri A, Bertuzzi T, Battilani P, 2007. Studies on Aspergillus section Flavi isolated from maize in northern Italy. Int J Food Microbiol 113:330-8.

Goto T, Peterson SW, Ito Y, Wicklaw DT, 1997. Mycotoxin producing ability of A. tamarii. Mycotoxins 44:17-20.

Italian Ministry of Health, 2004. Metodi di campionamento e di analisi per la ricerca di aflatossine nei formaggi. In: Official Journal, L IX/25664/F.5.b.b.2/P, 24/08/2004.

Ito Y, Peterson SW, Wicklaw DT, Goto T, 2001. Aspergillus pseudotamarii, a new aflatoxin producing species in Aspergillus section Flavi. Mycol Res 105:233-9.

Kebede H, Abbas HK, Fisher DK, Bellaloui N, 2012. Relationship between aflatoxin contamination and physiological responses of corn plants under drought and heat stress. Toxins 4:1385-403.

Kurtzman CP, Horn BW, Hesseltine C, 1987. Aspergillus nominus a new aflatoxin producing species related to A. flavus and A. tamarii. A Van Leeuw J Microb 53:147-58.

Manetta AC, Giammarco M, Di Giuseppe L, Fusaro I, Gramenzi A, Formigoni A, Vignola G, Lambertini L, 2009. Distribution of aflatoxin M1 during Grana Padano cheese production from naturally contaminated milk. Food Chem 113:595-9.

Marchetti G, Serraino A, Giacometti F,
Bonfante E, Rosmini R, 2013. Rassegna sulle aflatossine negli alimenti e nei mangimi: fonti di contaminazione per l'uomo e controllo. Ind Aliment 52:7-19.

Masoero F, Gallo A, Moschini M, Piva G, Diaz D, 2007. Carryover of aflatoxin from feed to milk in dairy cows with low or high somatic cell counts. Animal 1:1344-50.

Minervini F, Stea G, Visconti A, 1998. Survey on aflatoxins content in feed, milk and bovine and buffalo dairy products. In: Proceedings of the Special Project Ameliorating Quality of Food, 1998 July 9, Florence, Italy. Istituto Nazionale di Coordinamento AgroIndustria - CNR, Bari, Italy, pp 97-104.

Pietri A, Bertuzzi T, Pallaroni L, Piva G, 2004. Occurrence of mycotoxins and egosterol in maize harvested during five years in northern Italy. Food Addit Contam A 21:479-87.

Prandini A, Tansini G, Sigolo S, Filippi L, Laporta M, Piva G, 2009. On the occurrence of aflatoxin M1 in milk and dairy products. Food Chem Toxicol 47:984-91.

Ricci B, Canestrari G, Pizzamiglio V, Biancardi A, Merialdi G, Giacometti F, Nocetti M, Serraino A, Formigoni A, 2015. Gossypol content of cotton free commercial feed for dairy cows. Ital J Food Safety 4:5174.

Serraino A, Trevisani M, Boscolo D, Rosmini R, 2003. Contaminazione da AFM1 nel latte in Italia. Valutazione quantitativa del rischio per il consumatore. Ind Aliment 42:1113-9.

Trevisani M, Farkas Z, Serraino A, Zambrini AV, Pizzamiglio V, Giacometti F, Ámbrus A. 2014. Analysis of industry-generated data. Part 1: a baseline for the development of a tool to assist the milk industry in designing sampling plans for controlling aflatoxin M1 in milk. Food Addit Contam A 31:1246-56.

Veldman A, Meijst JAC, Borggreve GJ, Heeresvan der Tol JJ, 1992. Carry-over of aflatoxin from cow's food to milk. Anim Prod 55:163-8. 